\title{
Comparison of Sleep EEG Profiles of Patients Suffering from Restless Legs Syndrome, Restless Legs Syndrome and Depressive Symptoms, and Major Depressive Disorders
}

\author{
Serge Brand ${ }^{a} \quad$ Antreas Lehtinen $^{a}$ Martin Hatzinger ${ }^{b}$ Edith Holsboer-Trachsler ${ }^{a}$ \\ ${ }^{a}$ Depression Research Unit, Psychiatric Hospital of the University of Basel, and b Psychiatric Outpatient Department, \\ University Hospital Basel, Basel, Switzerland
}

\section{Key Words}

Depressive symptoms • Major depressive disorders • Restless legs syndrome $\cdot$ Polysomnography $\cdot$ Sleep disorders

\begin{abstract}
Background: Depressive disorders and restless legs syndrome (RLS) demand particular attention because sleepiness, daytime fatigue and loss of interest are symptoms attributable to both depressive disorders and RLS. Moreover, a high comorbidity rate is observed. The aim of the present study was to compare polysomnographic data of patients suffering from RLS, RLS and depressive symptoms, and major depressive disorders (MDD). Methods: Sleep EEG recordings of patients suffering from RLS $(n=25), R L S$ and depressive symptoms $(n=38)$, as well as MDD $(n=15)$ were compared. Results: Compared to patients with MDD, both groups with RLS had statistically decreased values of sleep continuity, including sleep efficiency, sleep onset latency and wakening after sleep onset. Patients with RLS or RLS and depressive symptoms had also decreased slow-wave sleep compared to patients with MDD. Conclusions: Objective sleep assessment supports previous findings: RLS is a disorder seriously affecting sleep, even compared to MDD. Concomitant symptoms of depression do not seem to additionally deteriorate sleep, though they trigger differences in treatment.
\end{abstract}

Copyright $\odot 2009$ S. Karger AG, Basel

\section{KARGER}

Fax +4161306 1234 E-Mail karger@karger.ch www.karger.com
(C) 2009 S. Karger AG, Basel

0302-282X/10/0611-0041\$26.00/0

Accessible online at:

www.karger.com/nps

\section{Introduction}

Sleep is strongly associated with daily well-being and functioning [1], learning capacity and academic performance [2]. Chronic sleep disturbances decrease physical and psychological functioning in both adolescents [3] and adults [1]. Furthermore, sleep complaints and insomnia in adults seem to be on the increase worldwide $[4,5]$.

Amongst the variety of possible factors adversely affecting sleep, for several reasons, depressive disorders and restless legs syndrome (RLS) demand particular attention. First, depressive and sleep disorders are highly associated [6-11]. Second, poor sleep is predictive of further episodes of depressive disorders [12].

The relation between RLS and depressive symptoms (DS) is complex but appears to be common; overlapping symptoms include deteriorated sleep, decreased mood and daily functioning, daytime fatigue, reduced attention, decreased libido [8] and daytime sleepiness [13]. RLS is considered a distressing sensorimotor disorder occurring with $5-10 \%$ of prevalence in the USA and other Western countries $[8,14,15]$, and alterations in iron-dopamine connections have been considered in its etiology $[16,17]$. In contrast, depressive disorders are seen as forms of mental disorder caused by biological (e.g. dysfunctional neuronal activity [18]), psychological (e.g. dysfunction-

Serge Brand, $\mathrm{PhD}$

Psychiatric Hospital of the University of Basel, Depression Research Unit

Wilhelm Klein-Strasse 27

$\mathrm{CH}-4025$ Basel (Switzerland)

Tel. +41 61325 5114, Fax +4161325 5513, E-Mail serge.brand@ upkbs.ch 
al thoughts [19]) and social (lack or dearth of or dissatisfying social feedback [20]) factors.

In patients suffering from RLS, light sleep (stages 1 and 2 ) is increased; slow-wave sleep (SWS; stages 3 and 4) and rapid eye movement (REM) sleep are decreased, with delayed sleep onset and REM latency [21, 22]. As a consequence, sleep is nonrestoring. Furthermore, a common neurobiological cause for both RLS and sleep disturbances has not been detected so far [23]. In contrast, for depressive disorders, there is evidence that sleep is impaired due to altered neuroendocrine activity, leading to markedly shortened REM sleep latency, increased REM sleep and REM density, as well as poor sleep efficiency (cf. [12]).

Despite their different etiologies, co-occurrence of RLS and DS is often observed (cf. [7-11]), though the direction of the relation is complex. There is evidence that the onset of RLS often precedes the onset of depressive or other psychiatric disorders. For example, Winkelmann et al. [10] reported that the lifetime prevalence rates for major depression also exceeded controls [36.9 vs. $15.2 \%$; odds ratio $(\mathrm{OR})=3.30,95 \% \mathrm{CI}=2.1-5.0]$, with the majority $(76.7 \%)$ reporting the onset of depression after that of RLS. Furthermore, $83.3 \%$ of the patients with dysthymia, $63.6 \%$ of those with general anxiety disorders and $60 \%$ of those with panic disorder reported the occurrence of RLS before the onset of the psychiatric disorder. Moreover, treatment of RLS with dopaminergic agents leads to markedly reduced DS [24].

Given these considerations, one might ask to what extent sleep is impaired in patients suffering from RLS and concomitant DS. Surprisingly, no study has compared polysomnographic data from patients suffering from RLS, and RLS and DS, with those of patients suffering from major depressive disorders (MDD). The aim of the present study was therefore to gain a deeper insight into the nature of the polysomnographically recorded sleep of patients with RLS alone or RLS in combination with DS, if compared to the sleep of patients suffering from MDD. We hold that the results may be important for further accurate treatment of patients with RLS.

We formulated the following 3 hypotheses. First, following previous research (e.g. [12, 21, 22]), we expected increased REM sleep latency, decreased REM sleep and less SWS in patients with RLS when compared to patients suffering from MDD. Second, following Coccagna and Luganesi [21], we anticipated more awakenings and more light sleep (stages 1 and 2) in patients suffering from RLS, again compared to those with MDD. Third, given that DS and RLS show a high overlap in symptomatology (cf. [8, 13]), we expected higher rates of antidepressant medica- tion in patients suffering from both RLS and DS, when compared to the rates for those suffering from RLS without DS.

Moreover, we explored to what extent differences with respect to sleep, periodic limb movements (PLMs) and arousals between patients suffering from RLS with or without DS might emerge and to what extent these 2 groups also differ from patients suffering from MDD. Put in other terms: we explored if the combination of RLS and DS may have additive effects leading to an increase in sleep deterioration compared to patients suffering exclusively from RLS and patients with MDD.

\section{Methods}

Sample and Procedure

A total of 78 patients [ 41 females, 37 males; mean age $=51.66$ years $(\mathrm{SD}=12.89)]$ took part in the study. Of those, 25 were patients suffering from RLS [mean age $=53.32$ years $(\mathrm{SD}=16.23) ; 9$ female and 16 male patients; labeled the 'group with RLS']; 38 were patients suffering from both RLS and DS [mean age $=50.20$ years ( $\mathrm{SD}=14.42) ; 21$ female and 17 male patients; labeled the 'group with RLS and DS']; and 15 were patients suffering from MDD [mean age $=51.47$ years $(S D=8.04) ; 11$ females and 4 males; labeled the 'group with MDD']. The 3 groups did not differ with respect to gender $\left[\mathrm{X}^{2}(2)=5.46, \mathrm{p}=.07\right)^{1}$ nor with respect to age: $[\mathrm{F}(2,75)=0.37, \mathrm{p}=0.69]$.

The procedure was as follows: for patients suffering from RLS, patients complaining about poor, nonrestoring sleep were entered in the sleep research unit (SRU) on referral. Then, a semistructured interview was conducted by a professional and experienced psychiatrist (M.H.). This covered sleep history, psychiatric examination according to the DSM-IV criteria [25] and current medication; physical examination and laboratory chemistry were performed afterwards. For polysomnographic recording, the patients slept in the SRU for 1 night. When the data elaboration was completed, the results were interpreted and explained to the patients. Afterwards, a rationale for therapy treatment was decided on and therapy was initiated.

For patients suffering from MDD, a structured clinical interview (SCID; [26]), including also items related to RLS and PLMs, was conducted. Patients suffering form MDD were also part of an ongoing study. This sample has already been largely described in Hatzinger et al. [12]. For short, after a washout phase of 1 week, all the 15 patients were treated with trimipramine monotherapy for 6 consecutive weeks. Sleep electroencephalography (EEG) recordings were performed 1 week after the beginning of treatment with trimipramine.

The local ethics committee approved the study.

1 Descriptively, gender distribution was not balanced. For this reason, preliminary computations were performed with gender as covariate. However, no systematic bias due to the factor gender as covariate could be detected. 
Table 1. Patients suffering from RLS with or without DS, and with or without sleep-altering medications

\begin{tabular}{lll}
\hline & Medications & \\
\cline { 2 - 3 } & medications altering sleep & no medication or medication not altering sleep \\
\hline $\begin{array}{l}\text { Group with RLS } \\
(\mathrm{n}=25)\end{array}$ & $\begin{array}{l}\mathrm{n}=10 \\
\text { benzodiazepines (3), methylphenidate (1), trimipramine (1), } \\
\text { amitriptyline (1), trazodone (1), pramipexole (1), levodopa (1) }\end{array}$ & $\begin{array}{l}\mathrm{n}=15 \\
\text { products against heart disease (5) }\end{array}$ \\
\hline $\begin{array}{lll}\text { Group with RLS } \\
\text { and DS ( } \mathrm{n}=38)\end{array}$ & $\begin{array}{l}\mathrm{n}=28 \\
\text { benzodiazepines (7), trimipramine (7), fluoxetine (1), sertra- }\end{array}$ & $\begin{array}{l}\mathrm{n}=10 \\
\text { 7 patients without any medication, }\end{array}$ \\
& $\begin{array}{l}\text { line (1), amitriptyline (1), escilatropram (4), mianserin (2), } \\
\text { paroxetine (4), trazodone (2), reboxetine (2), mirtazapine (1), }\end{array}$ & cardiovascular medications (3) \\
& $\begin{array}{l}\text { zopiclone (1), zolpidem (1), venlafaxine (1), pramipexole (1), } \\
\text { levodopa (2), lamotrigine (1), risperidone (2), quetiapine (1) }\end{array}$ & \\
\hline
\end{tabular}

Number in parentheses $=$ number of counts.

\section{Materials}

Assessing RLS during Diagnostic Interview

Following Walters [27], Shapira [28] and Allen et al. [6], a diagnosis of RLS was given if a patient answered 'yes' to the following 4 questions: (i) do you feel an urge to move the legs, normally accompanied by uncomfortable and unpleasant leg sensations; (ii) do symptoms worsen when lying or sitting; (iii) are symptoms at least partially relieved by movement, and (iv) are symptoms worse in the evening or at night?

Assessing Sleep and RLS with Polysomnography

All patients slept in the SRU for 1 night. Sleep was recorded between 11 p.m. (lights off) and 7 a.m. (lights on) using standard procedures of polysomnography: horizontal electro-oculography, submental myography and EEG (C3-A2, C4-A1, C3-C4) as well as electrocardiography. The sleep records were visually scored by 2 experienced raters according to standardized criteria [29]. Twenty percent of the sleep records were independently double-checked. The interrater reliability was $r=0.92$. The sleep parameters were analyzed according to the definitions in the standard program described by Lauer et al. [30]. In addition to the common sleep variables, for patients suffering from RLS, the PLM index and arousals were assessed.

Assessing PLMs

Following the Atlas Task Force [31], we labeled a PLM if sequences of extensions or flexions of lower limbs occurred at least 4 times consecutively for $>5 \mathrm{~s}$, if the intervals lasted not more than $90 \mathrm{~s}$, and if the interval between the sequences lasted between 20 and $40 \mathrm{~s}$. To assess PLMs, a movement electrode linked with the sleep EEG recorder was placed on both legs.

\section{Assessing DS}

An MDD was diagnosed if during the SCID (German version: [26]) a patient indicated to suffer severely from changes in behavior, cognition and emotion such as disturbed sleep, loss of motivation and interest, withdrawal from social activities and contacts, difficulties in concentrating, feelings of being guilty and worth- less, or decreased or increased weight. DS were diagnosed if a patient indicated to suffer a little to moderately from the changes in behavior, cognition and emotion described above.

\section{Pretreatment with Medication}

This diagnostic interview also covered current medication intake (see table 1). Daily clinical experience shows intake of different medications in people suffering from sleep disturbances. Thus, before performing definitive statistical analyses, we explored the possibility that sleep values might be biased because of drug pretreatment (see table 1 for overview). To this end, we compared the sleep values for patients pretreated with sleep-influencing medicaments with those of patients without drug treatment or taking medication without any influence on sleep. Ten $(40 \%)$ of the 25 patients in the RLS group were pretreated with sleep-altering medicaments; the sleep value means did not differ significantly (all $t<1)$. Twenty-eight $(73.7 \%)$ of the 38 patients suffering from RLS and DS were pretreated with sleep-altering medicaments; again, the mean sleep values did not differ significantly (all $t<1$ ). We also explored the possibility that different types of medication could alter sleep continuity and sleep architecture in different directions, leading to possible zero-effects of mean values; however, this was not the case. Therefore, it was not necessary to perform subsequent statistical analyses controlling for medication, nor were data from individual patients excluded from further analyses.

Patients suffering from MDD were treated with a monotherapy of trimipramine.

\section{Statistical Analyses}

The gender distributions of the 3 groups were compared with a $\chi^{2}$ test. Mean differences in sleep variables were calculated with one-way ANOVAs, and post-hoc tests were performed after Games-Howell. For exploratory and descriptive reasons, post-hoc tests were also reported for ANOVAs without significant $\mathrm{p}$ values. The post-hoc procedure after Games-Howell is readily applicable where group sizes are unequal; furthermore, homogeneity of variances is not mandatory [32]. $\chi^{2}$ tests and OR calculations were 
Table 2. Statistical overview of sleep continuity in patients suffering from RLS, from RLS and DS and from MDD

\begin{tabular}{|c|c|c|c|c|c|c|c|}
\hline \multirow[t]{3}{*}{ Variables } & \multicolumn{4}{|l|}{ Groups } & \multirow{2}{*}{\multicolumn{3}{|c|}{$\begin{array}{l}\text { Statistical analyses } \\
\text { post-hoc tests after Games-Howell, } \\
\text { p }\end{array}$}} \\
\hline & \multirow[t]{2}{*}{$\begin{array}{l}\text { RLS } \\
(n=25)\end{array}$} & \multirow[t]{2}{*}{$\begin{array}{l}\text { RLS + DS } \\
(\mathrm{n}=38)\end{array}$} & \multirow[t]{2}{*}{$\begin{array}{l}\text { MDD } \\
(n=15)\end{array}$} & \multirow[t]{2}{*}{ ANOVA F (d.f.), p } & & & \\
\hline & & & & & $\begin{array}{l}\text { RLS vs. } \\
\text { RLS + DS }\end{array}$ & $\begin{array}{l}\text { RLS } \\
\text { vs. MDD }\end{array}$ & $\begin{array}{l}\text { RLS + DS } \\
\text { vs. MDD }\end{array}$ \\
\hline $\mathrm{TIB}, \min$ & $480.00 \pm 54.00$ & $449.63 \pm 73.05$ & $510.27 \pm 40.39$ & $(21,75)=5.48,0.006$ & 0.110 & 0.140 & 0.001 \\
\hline SPT, min & $438.80 \pm 87.54$ & $400.00 \pm 94.45$ & $482.6 \pm 39.73$ & $(2,75)=5.42,0.006$ & 0.248 & 0.092 & 0.000 \\
\hline TST, min & $360.92 \pm 95.25$ & $331.26 \pm 108.88$ & $453.00 \pm 60.99$ & $(2,75)=8.45,0.001$ & 0.490 & 0.002 & 0.000 \\
\hline SE TST/SPT, \% & $82.98 \pm 15.33$ & $82.61 \pm 19.27$ & $93.64 \pm 7.98$ & $(2,75)=2.99,0.005$ & 0.998 & 0.017 & 0.013 \\
\hline WASO, $\min$ & $89.65 \pm 82.73$ & $77.38 \pm 70.34$ & $38.00 \pm 36.55$ & $(2,75)=2.49,0.092$ & 0.830 & 0.086 & 0.004 \\
\hline $\mathrm{SOL}, \min$ & $29.8 \pm 50.46$ & $41.72 \pm 58.22$ & $13.17 \pm 12.63$ & $(2,75)=1.78,0.175$ & 0.670 & 0.275 & 0.019 \\
\hline
\end{tabular}

TIB = Time in bed; SPT = sleep period time; TST = total sleep time; SE = sleep efficiency; WASO = wakening after sleep onset; $\mathrm{SOL}=$ sleep onset latency.

performed to explore the distribution of antidepressant medication between the groups of patients suffering from RLS with or without DS. Correlations were performed using Pearson's r (2tailed). Test results with an $\alpha$-error below 0.05 are reported as significant. Analyses were conducted using SPSS 15.0 for Windows.

\section{Results}

Sleep continuity, sleep architecture and REM sleep were compared between the groups with RLS, with RLS and DS, and with MDD.

\section{Sleep Continuity}

Table 2 provides an overview of the descriptive and inferential statistics with respect to sleep continuity.

Significant mean differences were observed for time in bed, sleep period time, total sleep time and sleep efficiency. No statistically significant mean differences were observed for wakening after sleep onset and sleep onset latency. Post-hoc analyses showed that there were no mean differences between the group with RLS and the group with RLS and DS. Compared to the group with MDD, the group with RLS showed decreased values with respect to total sleep time and sleep efficiency, whereas the group with RLS and DS showed decreased values with respect to time in bed, sleep period time, total sleep time, sleep efficiency, wakening after sleep onset and sleep onset latency.

In sum, compared to patients suffering from MDD, patients with RLS did show more unfavorable values of sleep continuity.

\section{Sleep Architecture}

Table 3 provides the overview of the descriptive and inferential statistics with respect to sleep architecture.

Significant mean differences between the groups with RLS, RLS + DS and MDD were observed for stage 3 (minutes) and for SWS, whereas for all other dimensions related to sleep architecture no significant mean differences were found.

For stage 3 sleep, post-hoc analyses revealed that the groups with RLS (with/without DS) did not differ, whereas both RLS groups showed significantly decreased values compared to the group with MDD. For SWS, a similar pattern of results was found, although the difference between the RLS with DS group and the MDD group did not quite reach statistical significance.

Taken together, compared to patients suffering from MDD, those with RLS had decreased stage 3 and SWS.

\section{REM Sleep}

Table 4 provides an overview of the descriptive and inferential statistics with respect to REM sleep.

Significant mean differences between the groups RLS, RLS + DS and MDD were found for the REM sleep time (minutes, percent) and the REM sleep latency (minutes). Post-hoc analyses showed that the RLS groups did not differ from each other, whereas both the group with RLS and the group with RLS + DS did differ from the group with MDD, with significantly less REM sleep (minutes) and with a significantly increased REM sleep latency. 
Table 3. Statistical overview of sleep architecture in patients suffering from RLS, from RLS and DS and from MDD

\begin{tabular}{|c|c|c|c|c|c|c|c|}
\hline \multirow[t]{3}{*}{ Variables } & \multicolumn{4}{|l|}{ Goups } & \multirow{2}{*}{\multicolumn{3}{|c|}{$\begin{array}{l}\text { Statistical analyses } \\
\text { post-hoc tests after Games-Howell, } \\
\text { p }\end{array}$}} \\
\hline & \multirow[t]{2}{*}{ RLS } & \multirow[t]{2}{*}{$\mathrm{RLS}+\mathrm{DS}$} & \multirow[t]{2}{*}{ MDD } & \multirow[t]{2}{*}{ ANOVA, F (d.f.), p } & & & \\
\hline & & & & & $\begin{array}{l}\text { RLS vs. } \\
\text { RLS + DS }\end{array}$ & $\begin{array}{l}\text { RLS vs. } \\
\text { MDD }\end{array}$ & $\begin{array}{l}\text { RLS + DS } \\
\text { vs. MDD }\end{array}$ \\
\hline Stage 1, min & $45.78 \pm 36.98$ & $41.76 \pm 29.51$ & $37.47 \pm 18.89$ & $(2,75)=0.36,0.701$ & 0.890 & 0.620 & 0.810 \\
\hline Stage 1, \% & $12.91 \pm 11.69$ & $16.28 \pm 21.92$ & $8.72 \pm 5.59$ & $(2,75)=1.12,0.333$ & 0.710 & 0.290 & 0.130 \\
\hline Stage $2, \min$ & $281.52 \pm 194.30$ & $238.59 \pm 72.05$ & $256.23 \pm 43.69$ & $(2,75)=0.93,0.400$ & 0.550 & 0.810 & 0.530 \\
\hline Stage $2, \%$ & $78.94 \pm 49.95$ & $75.85 \pm 26.82$ & $56.56 \pm 6.38$ & $(2,75)=2.26,0.112$ & 0.960 & 0.089 & 0.000 \\
\hline Stage 3 , min & $12.33 \pm 16.44$ & $20.53 \pm 30.41$ & $38.37 \pm 21.11$ & $(2,75)=5.11,0.008$ & 0.360 & 0.001 & 0.049 \\
\hline Stage 3, \% & $3.28 \pm 4.29$ & $8.97 \pm 17.57$ & $8.34 \pm 4.55$ & $(2,75)=1.60,0.210$ & 0.148 & 0.004 & 0.980 \\
\hline Stage 4 , min & $8.06 \pm 18.23$ & $8.76 \pm 17.16$ & $11.9 \pm 14.64$ & $(2,75)=0.26,0.775$ & 0.990 & 0.750 & 0.780 \\
\hline Stage $4, \%$ & $1.97 \pm 4.22$ & $4.48 \pm 13.76$ & $2.51 \pm 3.08$ & $(2,75)=0.52,0.593$ & 0.550 & 0.890 & 0.690 \\
\hline SWS, min & $20.38 \pm 29.90$ & $29.29 \pm 41.59$ & $50.27 \pm 31.38$ & $(2,75)=3.20,0.046$ & 0.590 & 0.016 & 0.130 \\
\hline SWS, \% & $5.25 \pm 7.27$ & $13.44 \pm 29.09$ & $10.86 \pm 6.59$ & $(2,75)=1.15,0.325$ & 0.230 & 0.045 & 0.860 \\
\hline
\end{tabular}

For exploratory and descriptive reasons, post-hoc tests were performed even if an ANOVA was not significant.

Table 4. Descriptive and statistical overview of REM sleep in patients suffering from RLS, from RLS and DS and from MDD

\begin{tabular}{|c|c|c|c|c|c|c|c|}
\hline \multirow[t]{3}{*}{ Variables } & \multicolumn{4}{|l|}{ Groups } & \multirow{2}{*}{\multicolumn{3}{|c|}{$\begin{array}{l}\text { Statistical analyses } \\
\text { post-hoc tests after Games-Howell, } \\
\text { p }\end{array}$}} \\
\hline & \multirow[t]{2}{*}{ RLS } & \multirow[t]{2}{*}{$\mathrm{RLS}+\mathrm{DS}$} & \multirow[t]{2}{*}{ MDD } & \multirow[t]{2}{*}{ ANOVA, F (d.f.), p } & & & \\
\hline & & & & & $\begin{array}{l}\text { RLS vs. } \\
\text { RLS + DS }\end{array}$ & $\begin{array}{l}\text { RLS vs. } \\
\text { MDD }\end{array}$ & $\begin{array}{l}\text { RLS + DS } \\
\text { vs. MDD }\end{array}$ \\
\hline REM sleep, min & $62.09 \pm 32.79$ & $54.74 \pm 30.36$ & $98.37 \pm 36.02$ & $(2,75)=10.04,0.000$ & 0.646 & 0.010 & 0.001 \\
\hline REM sleep, \% & $16.56 \pm 6.99$ & $15.79 \pm 8.55$ & $21.44 \pm 6.67$ & $(2,75)=3.09,0.045$ & 0.920 & 0.050 & 0.041 \\
\hline REM latency, min & $133.14 \pm 93.64$ & $134.67 \pm 71.08$ & $71.97 \pm 30.69$ & $(2,75)=4.21,0.019$ & 0.990 & 0.014 & 0.000 \\
\hline
\end{tabular}

For exploratory and descriptive reasons, post-hoc tests were performed even if an ANOVA was not significant.

Table 5. Correlations between PLM index and arousals in patients suffering from RLS

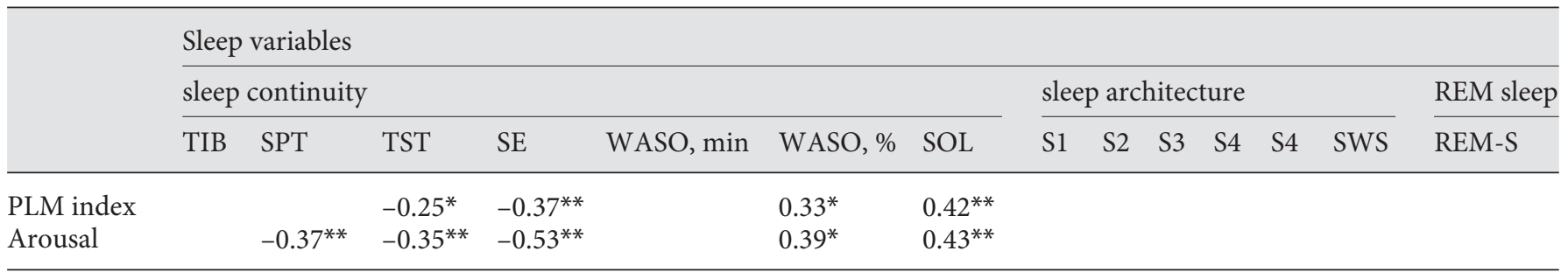

TIB = Time in bed; SPT = sleep period time; TST = total sleep time; SE = sleep efficiency; WASO = wakening after sleep onset; $\mathrm{SOL}=$ sleep onset latency; $\mathrm{S}=$ stage.

${ }^{*} \mathrm{p}<0.05 ;{ }^{* *} \mathrm{p}<0.01$. Pearson's correlation coefficients $\mathrm{r}$, 2-tailed; only correlation coefficients with $\mathrm{p}$ values $<0.05$ are displayed. 
Antidepressant Medication in Groups with RLS

Patients with RLS and DS received more antidepressants than those with RLS without DS $\left[\mathrm{X}^{2}(1)=13.36\right.$, $\mathrm{p}=$ 0.000]. OR showed that RLS patients with DS were 20 times more likely to receive antidepressants than RLS patients without $\mathrm{DS}(\mathrm{OR}=19.44 ; 95 \% \mathrm{CI}=3.19-118.40)$.

\section{PLM Index and Arousals in Patients Suffering from} $R L S$

To explore the association between PLM index and the number of arousals and other sleep variables in patients suffering from RLS, several correlations were computed (see table 5). First, we compared the PLM index and arousals across the 2 groups (i.e. RLS groups with or without DS) to determine whether they should be considered separately. However, neither the means for the PLM index [RLS group with DS: $\mathrm{M}=27.87, \mathrm{SD}=25.46$; RLS group without DS: $\mathrm{M}=34.41, \mathrm{SD}=32.32$; $\mathrm{t}(59)=0.88$, $\mathrm{p}=0.382$ ], nor the mean number of arousals [RLS group with DS: $\mathrm{M}=12.17, \mathrm{SD}=18.85$; RLS group without DS: $M=9.53, S D=5.03 ; t(59)=-0.65, p=0.516]$ differed significantly. Therefore, separate analyses were not performed.

Table 5 provides the correlation matrix between sleep variables, PLM index and arousals in patients suffering from RLS.

The general pattern of results suggests that both the PLM index and arousals are negatively associated with the duration and the onset of sleep, whereas values related to sleep architecture and REM sleep were not significantly associated.

\section{Discussion}

The key findings of the present study are that, compared to patients suffering from MDD, patients with RLS show a particular pattern of polysomnographically measured impaired sleep, and that patients suffering from RLS with or without DS do not differ from each other with respect to sleep, but concerning premedication.

Three hypotheses were initially formulated and each of these is considered in turn.

With the first hypothesis we expected increased REM sleep latency, decreased REM sleep and decreased SWS in patients with RLS when compared to patients suffering from MDD. The hypothesis was fully confirmed: patients with RLS showed a decreased REM sleep and REM sleep latency compared to those suffering from MDD. This pattern of results fits well with a wealth of previous re- search findings (cf. [7-12, 22]). Moreover, patients with RLS did also show a statistically decreased stage 3 and SWS. Thus, whereas in patients suffering from MDD the SWS/REM sleep ratio was in favor of REM sleep due to the underlying neuroendocrine regulation of increased CRF and cortisol (see Hatzinger et al. [12]), it does not seem conceivable to implicitly deduce that in patients suffering from RLS the SWS/REM sleep ratio is in favor of SWS.

Rather, following the second hypothesis, patients with RLS should show increased light sleep. Though not statistically significant, as the data in table 3 suggest, this was also the case in the present study, supporting previous research $[21,22]$. The reason why these mean differences were statistically not significant remains undisclosed, though one might speculate that the high standard deviations within and between the groups (see table 3) may have led to descriptively, though not statistically, significant different means.

Taken together, the present data confirm the observation that RLS is a distressing sensorimotor disorder which impairs the onset and continuity of sleep (cf. [8, $14,15])$ and that an underlying neuroendocrine mechanism leading to RLS-specific sleep patterns seems rather unlikely.

Our third hypothesis was also confirmed: patients with RLS and DS were more likely to be medically pretreated with antidepressants than patients with RLS only. Given that DS and RLS symptoms have a high degree of overlap and that RLS is 'the most common disorder you never heard of' [7], we hold that this finding is of particular concern for various reasons. First, DS may have been erroneously perceived as indicative of the target disease while the underlying RLS remained undetected. Second, there is some evidence that antidepressants such as fluoxetine and SSRIs may increase PLMs and consequently also RLS (for detailed discussion, see Picchietti and Winkelman [8], and Rottach et al. [33]). However, in this respect, recent findings suggest that the occurrence and duration of SSRI-induced RLS symptoms and PLM are more complex [33]. Furthermore, Ulfberg et al. could not affirm that people affected by RLS were more often consumers of antidepressant medication [9]. Third, our results are in line with findings which highlight that successful treatment of RLS also leads to reduced symptoms of depression (cf. [24]).

The aim of the explorative approach was to detect if along with RLS the diagnosis of concomitant DS may lead to differences in objectively assessed sleep patterns. However, RLS patients suffering from concomitant depressive 
disorders differed from RLS patients without DS neither in the PLM index and arousals nor in sleep. Thus, the data suggest that DS concomitant to RLS have no additive effects, that is to say: DS neither deteriorated nor attenuated the sleep of patients with RLS. The underlying neuroendocrine mechanisms could not be assessed, though one might speculate that the DS were not associated with an alteration in the hypothalamic-pituitary-adrenocortical axis activity such as to impact sleep in patients with RLS.

\section{Limitations}

Several considerations warrant against overgeneralization of the findings. First, because patients were recruited from only 1 study center, a systematic bias may not be excluded. Second, the samples themselves (descriptive gender distribution; medication intake) may not conclusively represent objective sleep variables, though virtually no sample of patients may fully represent the entire range of disorders. Importantly, intake of a wide range of medication prior to referral to an SRU and prior to objective sleep assessment is a clinical reality. For the present study, we did not find any medication-related biases in the sleep data despite thorough statistical checking, and it could be added that trimipramine has been found not to affect REM sleep [34], though another study reported increased REM sleep and decreased SWS with trimipramine [35]. Third, the findings showed that the groups with RLS and RLS + DS did not differ with respect to objectively assessed sleep variables, though they did vary with respect to symptoms. Importantly, even though it was impossible to assess what patients had said to their primary-care physicians before being referred to our SRU, it seems that they must have triggered different treatment rationales [36]. Fourth, expert ratings were made according to DSM-IV-diagnosed criteria for DS, but no self-reported assessment of depressive and anxiety symptoms was included. Future research should consider self-reports. Fifth, the small sample sizes of the different groups may have prevented us from detecting further group differences. In this view, though not statistically significant even if introduced as a covariate in the present study, issues related to gender distribution should always be taken into account. Sixth, the cross-sectional design did not allow us to draw any conclusions about the direction and the mechanisms of influence: whereas it has been repeatedly found that RLS may lead to mood and affective disorders (cf. [7-11]), one might also speculate about a dopamine deficit which may cause both RLS, DS and depressive disorders (cf. [37]).

Polysomnography, RLS and Depression

\section{Conclusions}

Objectively assessed sleep results show that RLS dramatically reduces sleep, even if compared to the sleep of patients suffering from MDD. No differences in sleep, PLM and arousal were found between RLS patients with or without DS. However, RLS patients were 20 times more likely to receive unfavorable first-line medication with antidepressants if they exhibited concomitant DS. This is of particular concern, since $81 \%$ of the RLS patients in an epidemiological study indicated they referred their complaints to a primary-care physician, but only $6.2 \%$ were given the diagnosis of RLS $[38,39]$, yet procedures for treatment of RLS have been successfully established [40]. Future research might emphasize possible favorable factors such as regular daytime activities (cf. [41, 42]) and might follow up pharmacological treatment of RLS with respect to treatment outcome, daily functioning and quality of life.

\section{Acknowledgements}

We thank Alexandre Mueller and Martin Walde for data entry. Next, we are grateful to Marielle König and Vladimir Djurdjevic, who handled the technical equipment and the polysomnographic scoring. We also thank Nick Emler (Surrey, UK) for proofreading the manuscript. Furthermore, we thank Lundbeck (Switzerland) for financial support in the form of an unrestricted grant (S.B.). Lundbeck had no influence on the study project, in particular not concerning data collection, data entry, data analyses, the interpretation of the data or the writing and the submission of the manuscript or the journal chosen for possible publication.

References

1 Banks S, Dinges DF: Behavioral and physiological consequences of sleep restriction. J Clin Sleep Med 2007;3:519-528.

2 Curcio G, Ferrara L, De Gennaro M: Sleep loss, learning capacity and academic performance. Sleep Med Rev 2006;10:323-337.

3 Roberts ER, Roberts CR, Duong HT: Chronic insomnia and its negative consequences for health and functioning of adolescents: a 12-month prospective study. J Adolesc Health 2008;42:294-302.

4 Morin CM, LeBlanc M, Daley M, Gregoire JP, Mérette C: Epidemiology of insomnia: prevalence, self-help treatments, consultations, and determinants of help-seeking behaviors. Sleep Med 2006;7:123-130.

$\checkmark 5$ Ohayon MM: Epidemiology of insomnia: what we know and what we still need to learn. Sleep Med Rev 2002;6:97-111. 
6 Allen RP, Picchietti D, Hening WA, Trenkwalder C, Walters AS, Montplaisir J: Restless legs syndrome: diagnostic criteria, special considerations and epidemiology: a report from the restless legs syndrome diagnosis and epidemiology workshop at the National Institutes of Health. Sleep Med 2003;4:101-119.

$\checkmark 7$ Hornyak M, Kopasz M, Berger M, Riemann D, Voderholzer U: Impact of sleep-related complaints on depressive symptoms in patients with restless legs syndrome. J Clin Psychiatry 2005;66:1139-1145.

$\checkmark 8$ Picchietti DL, Winkelman J: Restless legs syndrome, periodic limb movements in sleep, and depression. Sleep 2005;28:891898.

9 Ulfberg J, Bjorrvatn B, Leissner L, Gyring J, Karlsborg M, Regeur L, Skeidsvoll H, Polo O, Partinen M: Comorbidity in restless legs syndrome among a sample of Swedish adults. Sleep Med 2007;8:768-772.

-10 Winkelmann J, Prager M, Lieb R, Pfister H, Spiegel B, Wittchen HU, Holsboer F, Trenkwalder C, Ströhle A: 'Anxietas tibiarum': depression and anxiety disorders in patients with restless legs syndrome. J Neurol 2005; 252:67-71.

$\checkmark 11$ Lee HB, Hening WA, Allen RP, Kalaydjian AE, Earley CJ, Eaton WW, Lyketsos CG: Restless legs syndrome is associated with DSM-IV major depressive disorder and panic disorder in the community. J Neuropsychiatry Clin Neurosci 2008;20:101-105.

-12 Hatzinger M, Hemmeter UM, Brand S, Ising M, Holsboer-Trachsler E: Electroencephalographic sleep profiles in treatment course and long-term outcome of major depression: association with DEX/DRH-test response. J Psych Res 2004;38:453-465.

$\checkmark 13$ Sethi KD: Restless legs syndrome sees the light of day. Lancet Neurol 2008;7:564-565.

14 Ferini-Strambi L: RLS-symptoms: differential diagnosis by history and clinical assessment. Sleep Med 2007;8:S3-S6.

-15 Hadjigeorgiou GM, Stefanidis I, Dardiotis E, Aggellakis K, Sakkas GK, Xiromerisiou G, Konitsiotis S, Paterakis K, Poultsidi A, Tsimourtou V, Ralli S, Gourgoulianis K, Zintzaras E: Low RLS prevalence and awareness in central Greece: an epidemiological survey. Eur J Neurol 2007; 14:1275-1280.

16 Winkelman JW: Considering the causes of RLS. Eur J Neurol 2006;13(suppl 3):8-14.
17 Allen RP: Finding the dopamine abnormality in RLS: the iron-dopamine connection evaluated in translational research. Sleep Med 2007;8(suppl 1):S17.

18 Davidson RJ, Pizzagalli D, Nitschke JB, Butnam K: Depression: perspectives from affective neuroscience. Annu Rev Psychol 2002; 53:545-574

19 Beck AT: Depression. Causes and Treatment. Philadelphia, University of Pennsylvania Press, 1967.

20 Lewinsohn PM: A behavioral approach to depression; in Friedman RJ, Katz MM (eds) The Psychology of Depression. New York, Wiley, 1974.

21 Coccagna G, Lugaresi E: Restless legs syndrome and nocturnal myoclonus. Int J Neurol 1982;15:77-87.

22 Hornyak M, Feige B, Voderholzer U, Philipsen A, Riemann D: Polysomnography findings in patients with restless legs syndrome and in healthy controls: a comparative observational study. Sleep 2007;30:861865.

23 Barrière G, Cazalets JR, Bioulac B, Tison F, Ghorayeb I: The restless legs syndrome. Prog Neurobiol 2005;77:139-165.

24 Saletu M, Anderer P, Saletu-Zyhlarz G, Hauer C, Saletu B: Acute placebo-controlled sleep laboratory studies and clinical followup with pramipexole in restless legs syndrome. Eur Arch Psychiatry Clin Neurosci 2002;252:185-194.

25 American Psychiatric Association: Diagnostic and Statistical Manual of Mental Disorders (ed 4). Washington, American Psychiatric Association, 2000

26 Wittchen HU, Zaudig M, Schramm E, Spengler P, Mombour W, Klug J, Horn R: Strukturiertes klinisches Interview für DSM-III-R. Deutschsprachige, erweiterte Bearbeitung der amerikanischen Originalversion des SCID von R.L. Spitzer, J.B.W. Williams, M. Gibbon. Weinhein, Beltz-Test, 1987

27 Walters AS, International Restless Legs Syndrome Study Group: Toward a better definition of the restless legs syndrome. Mov Disord 1995;10:634-642.

28 Schapira AHV: RLS patients: who are they? Eur J Neurol 2006;14(suppl 3):2-7.

29 Rechtschaffen A, Kales A: A manual of standardized terminology techniques and scoring system for sleep stages of human subjects. Bethesda, US Department of Health, Education and Welfare, Neurological Information Network, 1968.
30 Lauer C, Riemann D, Wiegand M, Berger M: From early to late adulthood: changes in EEG sleep of depressed patients and healthy volunteers. Biol Psychiatry 1991;29:979993.

31 The Atlas Task Force: Recording and scoring leg movements. Sleep 1993;16:748-759.

32 Diehl JM, Arbinger R: Einführung in die Inferenzstatistik (Introduction to inferential statistics). Eschborn bei Frankfurt am Main, Klotz, 2001

33 Rottach KG, Schner BM, Kirch MH, Zivotofsky AZ, Teufel LM, Gallwitz T, Messer T: Restless legs syndrome as side effects of second generation antidepressants. J Psychiatr Res 2008;43:70-75.

34 Wiegand M, Berger M, Zulley J, von Zerssen D: The effect of trimipramine on sleep in patients with major depressive disorder. Pharmacopsychiatry 1986;19:198-199.

35 Sonntag A, Rothe B, Guldner J, Yassouridis A, Holsboer F, Steiger A: Trimipramine and imipramine exert different effects on the sleep EEG and on nocturnal hormone secretion during treatment of major depression. Depression 1996;4:1-13.

$>36$ Kushida CA: Clinical presentation, diagnosis, and quality of life issues in restless legs syndrome. Am J Med 2007;120:S4-S12.

-37 Pania L, Gessab GL: Dopaminergic deficit and mood disorders. Int Clin Psychopharmacol 2002;17(suppl 4):S1-S7.

-38 Hening W, Walters AS, Allen RP, Montplaisier J, Myers A, Ferini-Strambi L: Impact, diagnosis and treatment of restless legs syndrome (RLS) in a primary care population: the REST (RLS epidemiology, symptoms, and treatment) primary care study. Sleep Med 2004;5:237-246

39 Chaudhuri KR, Forbes A, Grosset D, Lees A, Shneerson J, Schapira A, Stillman P, Williams, A: Diagnosing restless legs syndrome (RLS) in primary care. Curr Med Res Opin 2004;20:1785-1795.

40 Hening WA: Current guidelines and standards of practice for restless legs syndrome. Am J Med 2007;120:S22-S27.

41 Biddle SJH, Mutrie N: Psychology of Physical Activity. Determinants, Well-Being and Interventions (ed 2). London, Routledge, 2008.

42 Faulkner GEJ, Taylor AH: Exercise, Health and Mental Health. Emerging Relationships. London, Routledge, 2005. 